\title{
Định giá nhãn hiệu để xác định mức phí li-xăng trong các giao dịch chuyển quyền sử dụng nhãn hiệu
}

\author{
Hoàng Lan Phương ${ }^{*}$ \\ Truờng Đại học Khoa học Xã hội và Nhân văn, ĐHQGHN, 336 Nguyễn Trãi, Hà Nội, Việt Nam \\ Nhận ngày 07 tháng 8 năm 2017 \\ Chỉnh sửa ngày 14 tháng 9 năm 2017; Chấp nhận đăng ngày 28 tháng 9 năm 2017
}

\begin{abstract}
Tóm tắt: Chuyển quyền sử dụng nhãn hiệu (li-xăng nhãn hiệu) đang là phương thức được sử dụng rộng rãi bởi hiệu quả kinh tế của nó. Khác chuyển quyền sử dụng các tài sản hữu hình, khi li-xăng nhãn hiệu thì trong cùng một thời điểm nhiều chủ thể khác nhau ở các lãnh thổ khác nhau đều có thể sử dụng được loại tài sản vô hình là nhãn hiệu. Tại Việt Nam, giá của nhãn hiệu được li-xăng cũng như phương thức thanh toán phí li-xăng hiện nay rất đa dạng bởi chưa có một quy định pháp luật cụ thể nào để định hướng cho các bên xác định mức phí li-xăng trong các hợp đồng li-xăng nhãn hiệu cho phù hợp. Do là một loại giao dịch dân sự nên việc xác định mức phí li-xăng trong các giao dịch li-xăng nhãn hiệu phụ thuộc vào ý chí của các bên. Do đó, xuất phát thực tiễn, để các bên tham gia thoả thuận li-xăng nhãn hiệu định giá được nhãn hiệu để xác định mức phí li-xăng hợp lý thì cần đòi hỏi năng lực của các bên tham gia thoả thuận và cũng cần có một hệ thống pháp luật quy định cụ thể và rõ ràng hơn về nguyên tắc, phương pháp và tiêu chí về định giá nhãn hiệu trong các giao dịch li-xăng nhãn hiệu.
\end{abstract}

Tư khóa: Định giá, nhãn hiệu, phí li-xăng, chuyển quyền sử dụng.

\section{Dẫn nhập}

Là một trong các đối tượng của quyền sở hữu trí tuệ (SHTT), nhãn hiệu là đối tượng được các doanh nghiệp chú trọng trong việc bảo hộ và khai thác để tạo ra lợi nhuận. Một trong những phương thức khai thác giá trị kinh tế của nhãn hiệu tỏ ra hiệu quả nhất đó chính là việc chuyển quyền sử dụng nhãn hiệu. Khác với việc chuyển quyền sử dụng các tài sản hữu hình, tại một thời điểm, chủ sở hữu của tài sản hữu hình chỉ có thể chuyển quyền sử dụng tài sản hữu hình đó cho một chủ thể khác thì đối với nhãn

\footnotetext{
*ĐT.: 84-902585389.

Email: hoanglanphuong86@gmail.com

https://doi.org/10.25073/2588-1116/vnupam.4121
}

hiệu-một đối tượng của quyền SHTT, do đặc tính vô hình của chúng mà trong cùng một thời điểm chủ sở hữu có thể chuyển quyền sử dụng cho nhiều người sử dụng. Như vậy, trong cùng một thời điểm, cả chủ sở hữu và những người được chủ sở hữu cho phép đều có thể sử dụng nhãn hiệu. Ngoài ra, những người được chủ sở hữu cho phép có thể tiếp tục chuyển giao tiếp cho một hoặc những bên thứ ba khác sử dụng nhãn hiệu.

Chuyển quyền sử dụng nhãn hiệu (còn gọi là "li-xăng nhãn hiệu”) là việc chủ sở hữu nhãn hiệu (bên li-xăng) cho phép cá nhân, tổ chức khác (bên nhận li-xăng) sử dụng nhãn hiệu của mình trong một khoảng thời gian nhất định và trong một phạm vi nhất định. Khi li-xăng nhãn hiệu, chủ sở hữu nhãn hiệu sẽ thu về một khoản 
tiền (phí li-xăng) hoặc một lợi ích vật chất khác mà không cần phải trực tiếp sử dụng nhãn hiệu.

Trước khi chính thức bước vào một cuộc thương lượng để li-xăng nhãn hiệu thì bên li-xăng và bên nhận li-xăng nên có những sự chỉ dẫn tốt về giá trị của nhãn hiệu được li-xăng. Mục đích của việc định giá nhãn hiệu trong li-xăng nhãn hiệu là để các bên có thể tiến tới việc thoả thuận về khoản phí li-xăng [1]. Về bản chất, thoả thuận của hai bên về mức phí li-xăng trong hợp đồng li-xăng nhãn hiệu là một loại giao dịch dân sự và pháp luật phải tôn trọng ý chí của các bên tham gia giao dịch dân sự ${ }^{1}$. Do đó, việc đưa ra các phương pháp định giá là chỉ mang tính chất là chỉ dẫn, không phải là đưa ra những quy tắc bắt buộc để các bên phải áp dụng khi định giá nhãn hiệu nhằm mục đích đưa ra mức phí li-xăng trong các giao dịch li-xăng nhãn hiệu.

Nhãn hiệu là một đối tượng sở hữu công nghiệp (SHCN) nên các nội dung của hợp đồng sử dụng nhãn hiệu (còn gọi là "hơp đồng li-xăng nhãn hiệu”) phải có các nội dung quy định tại Điều 144 của Luật SHTT trong đó điểm e khoản 1 quy định nội dung bắt buộc phải có trong hợp đồng li-xăng các đối tượng của quyền SHCN nói chung và hợp đồng li-xăng nhãn hiệu nói riêng là "giá chuyển giao quyền sư dụng". Tuy nhiên, trong Luật SHTT cũng như các văn bản hướng dẫn thi hành Luật SHTT không có quy định nào về mức giá trần hay giá sàn trong các thoả thuận li-xăng nhãn hiệu, do đó, các bên có thể tự do thoả thuận về mức phí li-xăng và miễn là hợp đồng li-xăng có ghi nhận thoả thuận về giá để đáp ứng điều kiện để được đăng ký tại Cục SHTT. Như vậy, về trên lý thuyết, mức giá của hợp đồng li-xăng có thể bằng 0 hay một giá trị bất kỳ mang ý nghĩa tượng trưng như 1 USD hoặc 1 đồng.

Việc nghiên cứu vấn đề định giá nhãn hiệu để xác định mức phí li-xăng trong các giao dịch li-xăng nhãn hiệu cũng đã được quan tâm thể hiện trong các nghiên cứu trong nước và ngoài nước. Có thể kể tới các tác phẩm tiêu biểu sau:

\footnotetext{
$\overline{1}$ Điều 116 Bộ luật dân sự 2015.
}

(1) Các nghiên cứu trong nước

Trần Nam Long (2010), Nghiên cứu lý luận và thực tiễn nhằm xây dựng phương pháp định giá nhãn hiệu áp dụng trong giai đoạn công nghiệp hoá, hiện đại hoá tại Việt Nam, Đề tài cấp cơ sở của Viện Khoa học Sở hữu trí tuệ.

Đoàn Văn Trường (2009), Tuyển tập các phuoong pháp thẩm định giá trị tài sán, Nhà xuất bản Khoa học và Kỹ thuật.

Đào Minh Đức (2006), Một số vấn đề về định giá nhãn hiệu, Tạp chí Khoa học pháp lý số 11-12/2006

Phạm Hồng Quất (2009), Tổng quan tình hình định giá quốc tế về nhãn hiệu, Hội thảo "Các quy định pháp luật và thực tiễn định giá tài sản trí tuệ trong các doanh nghiệp phục vụ cổ phần hoá và giải quyết tranh chấp".

(2) Các nghiên cứu ngoài nước

Scott D. Phillips (2006), Determination of Royalty rates for Trademarks/Brands, Licensing Industry Merchandisers' Association Advanced Licensing Seminar.

John E. Elmore (2015), The Valuation of Trademark Related Intangible Property, Intangible Property Transfer Price Insights.

Tim Heberden (2011), Intellectual Property Valuation and Royalty Determination, Chapter 4 of "International Licensing and Technology Transfer: Practice and the law", edited by Adam Liberman, Peter Chrocziel and Russell Levine, Nhà xuất bản Wolters Kulwer Law \& Business.

Gordon V. Smith, Susan M. Richey (2013), Trademark Valuation, Nhà xuất bản Wiley.

Robert W. Gomulkiewicz, Xuan - Thao Nguyen, Danielle M. Conway (2011), Licensing Intellectual Property: Law and Application, Nhà xuất bản Wolters Kluwer, Second Edition.

Micheal J. Freno (2007), Trademark Valuation: Preserving Brand Equity, The Trademark Reporter

Neil J. Wilkof và Daniel Burkitt (2005), Trademark licensing, NXB Sweet \& Maxell Ltd., 
Russell L. Parr (2007), Royalty rates for licensing Intellectual Property, NXB John Wiley \& Sons, Inc.

Các nghiên cứu trong nước mới chỉ dừng lại ở việc đưa ra các phương pháp định giá nhã̃n hiệu mà còn ít đề cập đển việc định giá nhãn hiệu để xác định mức phí li-xăng trong các giao dịch li-xăng nhãn hiệu. Các công trình nghiên cứu nước ngoài đã đề cập tới các khía cạnh khác nhau về li-xăng nhãn hiệu, các phương pháp định giá nhãn hiệu để xác định mức phí li-xăng. Đây là những tham khảo rất có giá trị để áp dụng cho thực tiễn định giá nhãn hiệu trong các giao dịch li-xăng nhãn hiệu của Việt Nam.

\section{Thực tiễn định giá nhãn hiệu trong hợp đồng li-xăng nhãn hiệu tại Việt Nam hiện nay}

Sau khi Luật SHTT ra đời vào năm 2005, theo thống kê của Cục SHTT thì số nhãn hiệu được li-xăng và được đăng ký tại Cục SHTT trong vòng 10 năm từ năm 2006 đến năm 2016 là 8375 nhãn hiệu [2]. Trong đó, giá của các nhãn hiệu được li-xăng cũng như các phương thức thanh toán rất đa dạng. Có thể kể tới các phương thức thanh toán thông dụng như sau:

\subsection{Thanh toán theo tỷ lệ phần trăm doanh thu, giá bán sản phẩm}

Phí li-xăng được thanh toán theo tỷ lệ phần trăm doanh thu, giá bán sản phẩm vẫn là phương thức truyền thống và chiếm đa số trong các hợp đồng li-xăng nhãn hiệu.

Do pháp luật Việt Nam không quy định mức trần và mức sàn của giá nên có những trường hợp tỷ lệ phần trăm là rất cao. Chẳng hạn, năm 2008, Công ty The Phanu Group Limited (British Vigrin Islands) li-xăng nhãn hiệu "ANUPA" cho Công ty một thành viên Mantra (TP. Hồ Chí Minh) cho các sản phẩm thuộc nhóm 18: đồ da (Hòm bằng da hoặc bằng giả da; túi xách tay; ví phụ nữ; túi du lịch; túi dụng cụ du lịch bằng da, ví đàn ông) với mức tỷ lệ $50 \%$ giá bán sản phẩm mang nhãn hiệu được chuyển giao. Tuy nhiên, có những trường hợp tỷ lệ phần trăm lại rất thấp như hợp đồng lixăng giữa Công ty Shell Brands International (Thuỵ Sĩ) với Công ty TNHH Shell gas Viet nam (Đồng Nai) chỉ ở mức giá là $0,025 \%$ doanh thu bán tịnh sản phẩm mang nhãn hiệu "SHELL GAS" được chuyển giao trong cùng năm 2008. Hoặc phí li-xăng nhãn hiệu với mức giá $0,1 \%$ doanh thu thuần của sản phẩm mang nhãn hiệu được chuyển giao được áp dụng cho các sản phẩm thuộc nhóm 9 (dây và cáp điện) trong giao dịch li-xăng nhãn hiệu "TAYA" vào năm 2006 giữa TA YA Electric Wire \& Cable Co., Ltd. (Đài Loan) và Công ty cổ phần dây và cáp điện TA YA Việt Nam (Đồng Nai). Những trường hợp áp dụng tỷ lệ thấp như trên thường xảy ra đối với các hợp đồng li-xăng giữa công ty mẹ ở nước ngoài và công ty con hoặc công ty liên doanh ở Việt Nam. Việc ấn định mức giá thấp như vậy trong thực tế có thể giúp cho bên giao (công ty mẹ) không phải nộp thuế thu nhập hoặc nộp với mức thuế thu nhập ít đi theo quy định của pháp luật về thuế thu nhập doanh nghiệp [3].

\subsection{Thanh toán một lần}

Phương thức thanh toán một lần này chính là việc thanh toán trọn gói (Lumpsum payment). Phí li-xăng được thanh toán một lần có thể dưới dạng tiền mặt hoặc phần vốn góp. Tuy nhiên, phương thức thanh toán phí li-xăng một lần dưới dạng tiền mặt trên thực tế ít được áp dụng mà chủ yếu khoản tiền này được thể hiện dưới dạng góp vốn để tạo thành vốn điều lệ của công ty nhằm mục đích thành lập công ty liên doanh hoặc công ty con. Bản chất của việc góp vốn bằng nhãn hiệu chính là việc chủ sở hữu nhãn hiệu cho phép công ty mà mình tham gia góp vốn sử dụng nhãn hiệu của mình. Giá trị của quyền sử dụng nhãn hiệu chính là khoản tiền mà chủ sở hữu nhãn hiệu góp vốn vào công ty. Trên thực tế, bên nhận sẽ không phải thanh toán khoản tiền này cho chủ sở hữu nhãn hiệu mà chỉ ghi nhận khoản tiền đó dưới dạng phần vốn góp trong vốn điều lệ của mình. Quyền sở hữu nhãn hiệu vẫn thuộc về bên góp vốn tức là chủ sở hữu nhãn hiệu song việc định đoạt nhãn hiệu cũng bị hạn chế trong thời gian góp vốn trong 
trường hợp chủ sở hữu nhãn hiệu muốn chuyển nhượng quyền sở hữu (bán) nhãn hiệu đã góp vốn cho một bên thứ ba khác. Điều này nhằm mục đích để bảo vệ quyền lợi cho bên nhận quyền sử dụng nhãn hiệu cũng như để duy trì sự ồn định của việc góp vốn bằng giá trị quyền sử dụng nhãn hiệu. Điển hình của việc góp vốn bằng giá trị quyền sử dụng nhãn hiệu tại Việt Nam là Công ty TNHH Cà phê Trung Nguyên (Đắk Lắk) đã góp vốn bằng giá trị quyền sử dụng nhãn hiệu "TRUNG NGUYÊN" để thành lập Công ty Cổ phần Trung Nguyên (TP. Hồ Chí Minh) với giá trị nhãn hiệu là 45 tỷ đồng vào năm 2006 [4].

\subsection{Thanh toán môt lần và tỷ lệ phần trăm doanh thu, giá bán sản phẩm}

Phí li-xăng theo hình thức thanh toán này được thể hiện là một khoản tiền được thực hiện dưới dạng phần vốn góp và một khoản thu định kỳ theo tỷ lệ phần trăm doanh thu hoặc theo giá bán sản phẩm. Chẳng hạn, năm 2007, hợp đồng li-xăng nhãn hiệu "CHUGOKU" đăng ký tại Cục SHTT cho các sản phẩm sơn giữa Công ty CHUGOKU Marine Paints, Ltd. (Nhật Bản) và Công ty cổ phần Sơn Hải Phòng (Hải Phòng) được thực hiện dưới dạng góp vốn liên doanh bằng giá trị quyền sử dụng nhãn hiệu tương đương phần vốn góp vào Công ty là 70.000 USD và khoản thu định kỳ là $3 \%$ giá bán tịnh các sản phẩm mang nhãn hiệu được chuyển giao [5]. Hoặc Tổng công ty Thuỷ tinh và gốm sứ xây dựng Việt Nam (Viglacera) trong năm 2004 đã thực hiện 17 hợp đồng li-xăng nhãn hiệu [6] dưới hình thức góp vốn với trị giá quyền sử dụng nhãn hiệu với giá trị là từ 2 tỷ đến 10 tỷ đồng và khoản thu định kỳ đồng nhất ở mức $0,35 \%$ doanh thu của bên nhận ${ }^{2}$.

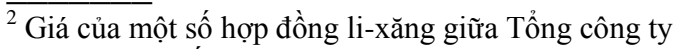
Thuỷ tinh và gốm sứ xây dựng Việt Nam (Viglacera) có phần góp vốn và thu lại một khoản phí li-xăng định kỳ để thành lập các công ty con như sau:

1. Công ty gốm xây dựng Hạ Long (TP. Hạ Long, Quảng Ninh): 9,5 tỷ đồng và $0,35 \%$ doanh thu

2. Công ty gốm xây dựng Đông Triều (Huyện Đông Triều, Quảng Ninh): 3,3 tỷ đồng và $0,35 \%$ doanh thu
}

\subsection{Thanh toán dưới dạng một khoản tiền thu trên một đơn vị sản phẩm}

Với khoản thu bằng một khoản tiền cố định trên một đơn vị sản phẩm, phí li-xăng thu được của bên li-xăng phụ thuộc vào doanh số của sản phẩm hơn là giá bán của sản phẩm của bên nhận li-xăng. Cách tính giá li-xăng này có những lợi thế nhất định cho bên li-xăng vì khoản phí li-xăng được xác định là một giá trị tuyệt đối nhân với số lượng sản phẩm. Cách tính này thực chất là sự kết hợp giữa cách tính theo khoản tiền cố định và tỷ lệ phần trăm doanh thu sản phẩm. Theo cách tính này, bên nhận li-xăng sẽ hạn chế được những rủi ro phải gánh chịu trong bối cảnh thị trường có nhiều biến động về giá cũng như có tính cạnh tranh cao về giá bán sản phẩm. Tuy nhiên, hiện nay cách tính giá li-xăng này chưa được phổ biến mà thông thường chỉ được áp dụng trong các giao dịch bên li-xăng và bên nhận li-xăng có hoạt động kinh doanh độc lập, không có mối quan hệ hợp tác, liên doanh liên kết, góp vốn giữa các bên. Điển hình cho việc thanh toán phí li-xăng theo hình thức này là hợp đồng li-xăng nhãn hiệu "VINATABA" giữa Tổng công ty thuốc lá Việt Nam (Hà Nội) và nhà máy thuốc lá Sài Gòn (TP. Hồ Chí Minh) với mức giá 500 đồng/bao 20 điếu năm 2005 [7].

\subsection{Trả một khoản tiền định kỳ theo tháng, năm}

\subsubsection{Trả phi li-xăng định kỳ theo năm}

Đối với phương thức trả phí li-xăng định kỳ hàng năm thì có hai phương thức để thanh toán mức phí li-xăng theo hình thức này:

\footnotetext{
3. Công ty Hải Vân - Viglacera (Huyện Vân Đồn, Quảng Ninh): 3,3 tỷ đồng và $0,35 \%$ doanh thu

4. Công ty kính Đáp Cầu (Thị xã Bắc Ninh, Bắc Ninh): 10 tỷ đồng và $0,35 \%$ doanh thu

5. Công ty vật liệu chịu lửa Cầu Đuống (Huyện Gia Lâm, Hà Nội): 3 tỷ đồng và $0,35 \%$ doanh thu

6. Công ty gốm xây dựng Từ Sơn (Huyện Từ Sơn, Bắc

Ninh): 4 tỷ đồng và $0,35 \%$ doanh thu

7. Công ty kinh doanh và xuất nhập khẩu (Quận Cầu Giấy, Hà Nội): 5 tỷ đồng và $0,35 \%$ doanh thu

8. Công ty đầu tư phát triển hạ tầng (Quận Tây Hồ, Hà Nội): 5 tỷ đồng và $0,35 \%$ doanh thu

9. Công ty cơ khí và xây dựng Viglacera (Huyện Từ Liêm, Hà Nội): 10 tỷ đồng và $0,35 \%$ doanh thu
} 
(i) Mức phi li-xăng được tính theo phương pháp kết hợ: tỷ lệ phần trăm theo doanh thu sản phẩm với mức phí li-xăng tối thiểu được ấn định từng năm, theo mức tăng dần theo năm như hợp đồng li-xăng nhãn hiệu "PIERRE CARDIN" của Công ty Pierre Cardin (Pháp) và Công ty Dịch vụ Tổng hợp Sài Gòn (TP. Hồ Chí Minh) cho các sản phẩm quần áo thời trang dành cho trẻ em thuộc nhóm 25 áp dụng cách tính kết hợp giữa tỷ lệ phần trăm giá bán tịnh sản phẩm $(5 \%)$ với mức phí li-xăng tối thiểu được ấn định bằng khoản tiền cụ thể tăng dần từ năm thứ nhất đến năm thứ 5 .

Cụ thể:

Năm thứ 1: 20000USD

Năm thứ 2: 32000USD

Năm thứ 3: 40000USD

Năm thứ 4: 40000USD

Năm thứ 5: 40000USD [8]

(ii) Mức phí li-xăng được tính bằng một khoản tiền định kỳ theo năm: bên nhận li-xăng sẽ trả một khoản tiền cố định theo năm cho bên li-xăng.

Năm 2008, Hợp đồng li-xăng của TCRWARE Co.,Ltd (Đài Loan) li-xăng nhãn hiệu "TAICERA, HÌNH" cho Công ty cổ phần Công nghiệp Gốm sứ TAICERA (Đồng Nai) với mức giá $200.000 \mathrm{USD} /$ năm cho các sản phẩm nhóm 11,19 và 21 [9].

\subsubsection{Trả phí li-xăng định kỳ theo tháng:}

Thông thường việc trả phí li-xăng theo tháng thường được áp dụng giữa các bên có quan hệ hợp tác với nhau trong kinh doanh trong lĩnh vực dịch vụ thương mại. Chẳng hạn, mức phí li-xăng trong hợp đồng li-xăng nhãn hiệu "DIMERCO" giữa Công ty Dimerco Express Holding Co., Ltd. (Bermuda) và Công ty Liên doanh TNHH Dimerco Vietfracht (TP. Hồ Chí Minh) năm 2006 như sau:

+ 5 năm đầu: 400 USD/tháng

+ Các năm tiếp theo (tính trên doanh thu thuần hàng năm của bên nhận li-xăng):

- 400 USD/tháng thấp hơn 5.000.000 USD doanh thu hàng năm
- 600 USD/tháng từ 5.000.000 USD đến 9.999.999 USD

- 1.000 USD/tháng từ 10.000.000 USD trở lên [10]

Trên thực tế, các hợp đồng li-xăng nhãn hiệu có mức phí li-xăng với những giá trị đa dạng. Có thể mức giá trong các hợp đồng li-xăng đã phản ánh được giá trị thực tế của nhãn hiệu được li-xăng, nhưng trong nhiều trường hợp mức giá li-xăng chưa phản ánh đúng giá trị hoặc là có thể cao hơn rất nhiều hoặc là có thể thấp hơn rất nhiều giá trị thực của nhãn hiệu được li-xăng. Vậy lựa chọn phương thức định giá nhãn hiệu nào để xác định một mức phí li-xăng phù hợp trong các hợp đồng li-xăng nhãn hiệu luôn là câu hỏi được đặt ra cho các bên trong quá trình thoả thuận để li-xăng nhãn hiệu.

\section{Các cách tiếp cận để định giá nhãn hiệu khi li-xăng nhãn hiệu}

Hợp đồng li-xăng nhãn hiệu chính là việc phân chia các lợi ích kinh tế trong tương lai của việc khai thác nhãn hiệu giữa bên li-xăng và bên nhận li-xăng. Đối với bên li-xăng, giá trị của giao dịch li-xăng nhãn hiệu được cho là giá trị hiện tại của khoản tiền nhận được sau khi trừ đi giá trị của các chi phí phải chịu để thực hiện hợp đồng li-xăng bao gồm cả các khoản bồi thường tiềm tàng hoặc các thu nhập đã được tính toán trước khi mà bên li-xăng không tự khai thác nhãn hiệu. Còn đối với bên nhận li-xăng, giá trị của giao dịch li-xăng nhãn hiệu là giá trị của các lợi ích kinh tế trong tương lai khi khai thác quyền đối với nhãn hiệu được li-xăng sau khi trừ đi giá trị hiện tại của các chi phí để nhận li-xăng [11].

Đối với bên li-xăng thì phí li-xăng rõ ràng là nguồn tiền đầu vào và đối với bên nhận li-xăng thì phí li-xăng là nguồn tiền đầu ra. Nguồn tiền này sẽ bị ảnh hưởng bởi thời hạn của hợp đồng li-xăng, lãnh thổ độc quyền, phạm vi sử dụng, quyền được li-xăng thứ cấp và việc độc quyền trong sử dụng nhãn hiệu. 
Về cơ bản sẽ có 3 cách tiếp cận để định giá nhãn hiệu: (i) Cách tiếp cận dựa trên chi phí; (ii) Cách tiếp cận dựa trên thu nhập; (iii) Cách tiếp cận dựa trên thị trường

\subsection{Cách tiếp cận dựa trên chi phí}

Cách tiếp cận dựa trên chi phí xác định giá trị của một tài sản trí tuệ bằng cách tính toán tổng chi phí phát sinh mà một doanh nghiệp bỏ ra để tạo ra và phát triển tài sản trí tuệ đang cần được định giá của doanh nghiệp đó. Tổng chi phí để tạo ra và phát triển tài sản trí tuệ được coi là một trong những yếu tố quyết định giá trị của tài sản trí tuệ đó.

Cách tiếp cận dựa trên chi phí gồm có ba phương pháp sau đây:

\section{(i) Phuoong pháp chi phi quá khú}

Phương pháp này xác định tổng chi phí phát sinh trong quá khứ để tạo ra và phát triển tài sản trí tuệ cần định giá. Tổng chi phí được coi như giá trị của tài sản trí tuệ đó.

Trên thực tế, phương pháp này không được áp dụng phổ biến bởi thiếu sót cơ bản là với bản chất "vô hình" của tài sản trí tuệ thì giá trị trong tương lai của loại tài sản này nhiều khi là rất lớn song phương pháp chi phí quá khứ đã không phản ánh được giá trị của tài sản trí tuệ trong tương lai là một điều rất hạn chế khi định giá tài sản trí tuệ theo phương pháp chi phí quá khứ. Ngoài ra, nếu sử dụng phương pháp này thì chỉ có thể đúng với sáng chế hoặc một đối tượng của quyền SHTT khác chứ không đúng với nhãn hiệu (đặc biệt khi nhãn hiệu đứng độc lập không gắn với bất cứ một đối tượng của quyền SHTT khác) bởi chi phí đầu tư để tạo ra một nhãn hiệu không thể là giá chuyển giao của nhãn hiệu trong các giao dịch li-xăng nhãn hiệu. Các chi phí mà doanh nghiệp bỏ ra để khởi tạo ra một nhãn hiệu không đồng nghĩa là giá trị của nhãn hiệu đó tại thời điểm mới được hình thành bằng số tiền mà doanh nghiệp đã đầu tư tạo ra nhãn hiệu bởi đối với một doanh nghiệp khác thì một nhãn hiệu ban đầu mới được tạo ra sẽ chẳng có nhiều ý nghĩa với họ bởi các doanh nghiệp đó chưa thấy được tiềm năng, giá trị, uy tín cũng như lợi nhuận sẽ được tạo ra khi họ sử dụng các nhãn hiệu mới được khởi tạo đó. Do vậy, giá trị của một nhãn hiệu không phải là chi phí đã bỏ ra để đầu tư hình thành nên nhãn hiệu mà là tổng hoà các giá trị khác như uy tín của doanh nghiệp trên thị trường, chất lượng sản phẩm mang nhãn hiệu, các hoạt động marketing, khả năng chiếm lĩnh thị trường của doanh nghiệp mang nhãn hiệu, phong cách phục vụ, hậu mãi,.. và việc nhãn hiệu đó gắn với các đối tượng của quyền SHTT khác như: sáng chế, kiểu dáng công nghiệp, tên thương mại hay bí mật kinh doanh,.. Vì vậy, phương pháp chi phí quá khứ không phải là phương pháp để xác định giá trị của nhãn hiệu.

\section{(ii) Phuoong pháp chi phí tái tạo}

Phương pháp này xác định tổng chi phí đầu tư để tạo ra và phát triển tài sản trí tuệ twoong đương với tài sản trí tuệ cần định giá theo cùng một cách thức vào thời điểm hiện tại. Các chi phí đầu tư nói trên bao gồm cả chi phí nghiên cứu và chi phí phát triển. Phương pháp này cũng không phù hợp để xác định giá trị của nhãn hiệu bởi các chi phí đầu tư để tạo ra và phát triển tài sản trí tuệ tương đương với tài sản trí tuệ cần định giá bao gồm cả "chi phí nghiên cứu" và "chi phí phát triển" song đối với nhãn hiệu thì không có "chi phí nghiên cứu" để tạo ra nhãn hiệu mà chỉ có "chi phí phát triển" nhãn hiệu. Chi phí nghiên cứu này chỉ có trong việc tạo ra một sáng chế, do đó, phương pháp này phù hợp với việc xác định giá trị của "sáng chế" chứ không phù hợp với là "nhãn hiệu".

\section{(iii) Phuoong pháp chi phi thay thế}

Phương pháp này xác định tổng chi phí cần thiết để có được (mua) tài sản trí tuệ tương đương với tài sản trí tuệ cần định giá do doanh nghiệp khác tạo ra và phát triển.

Về mặt lý thuyết thì phương pháp này chính xác hơn phương pháp chi phí quá khứ nhưng trong thực tế lại khó ước tính được chi phí thay thế hiện tại một cách khách quan. Ví dụ như khi định giá nhãn hiệu, cần bao nhiêu chi phí cho quảng cáo để đạt được mức độ quan tâm của thị trường với một nhãn hiệu là rất khó thực hiện. 
Phương pháp chi phí được sử dụng rộng rãi khi xác định giá trị của các tài sản hữu hình song nó không phải là phương pháp dành cho việc xác định giá trị của các tài sản trí tuệ như nhãn hiệu [12].

\subsection{Cách tiếp cận dựa trên thị trường}

Định giá nhãn hiệu dựa trên cách tiếp cận thị trường là việc ước tính giá trị của nhãn hiệu được định giá bằng cách phân tích, so sánh các giao dịch đối với các nhãn hiệu tương tụ.

Khi áp dụng phương pháp này cần phải đáp ứng các điều kiện sau:

(i) Dữ liệu của các nhãn hiệu sử dụng để tính toán phải chính xác;

(ii) Dữ liệu giá cả phải còn hiệu lực vào thời điểm định giá và đại diện cho thị trường vào thời điểm đó;

(iii) Tiến hành các điều chỉnh phù hợp để cho nhãn hiệu được so sánh và nhãn hiệu cần định giá trở nên dễ so sánh hơn;

(iv) Khi sử dụng các giao dịch trước đó cần phải thực hiện những điểu chỉnh cần thiết đối với sự thay đồi về thời gian, thay đổi trong nền kinh tế, trong ngành công nghiệp,.. [13].

Cách tiếp cận dựa trên thị trường gồm có ba phương pháp sau đây:

(i) Phương pháp đấu giá

Theo phương pháp này, giá trị của nhãn hiệu được xác định là mức giá cuối cùng trong cuộc đấu giá với những người mua tiềm năng có thông tin về tất cả các khía cạnh (kinh tế, kỹ thuật, pháp lý,..) của nhãn hiệu đó.

(ii) Phương pháp giá trị thị trường so sánh

Theo phương pháp này, giá trị của nhãn hiệu được xác định bằng cách so sánh với giá trị thị trường của nhãn hiệu tương đương hoặc nhãn hiệu trong giao dịch tương đương.

(iii) Phương pháp phí li-xăng so sánh

Theo phương pháp này, giá trị của nhãn hiệu được xác định bằng cách so sánh với thu nhập từ nhãn hiệu tương đương là đối tượng của thỏa thuận li-xăng trên cơ sở mức phí lixăng hợp lý giữa hai bên có quan hệ độc lập bên ngoài doanh nghiệp hoặc giữa doanh nghiệp với bên thứ ba.

Cách tiếp cận dựa trên thị trường tỏ ra ưu việt hơn cách tiếp cận dựa trên chi phí vì nó có tính khách quan hơn, độ tin cậy cao hơn và có những bằng chứng khách quan về giá thị trường (là sự thoả thuận giữa các bên giao dịch). Tuy nhiên, trong thực tế lại khó tìm được các giao dịch đối với các nhãn hiệu tương tự trên thị trường và các thông tin đáng tin cậy về chúng.

\subsection{Cách tiếp cận dựa trên thu nhập}

Nguyên tắc của việc định giá nhãn hiệu dựa trên thu nhập là việc xác định giá trị của nhãn hiệu sẽ được tính ra từ các lợi ích kinh tế (tức là thu nhập/dòng tiền) mà nó mang lại trong tương lai. Có 2 phương pháp trong cách tiếp cận dựa trên thu nhập gồm: "vốn hoá thu nhập" và "phân tích dòng tiền chiết khấu".

(i) Phương pháp "vốn hoá thu nhập"
Giá trị hiện tại của các lợi ích trong tương lai =

Phương pháp vốn hóa thu nhập ít được sử dụng vì thu nhập do nhãn hiệu mang lại thường không ổn định, đặc biệt là trong điều kiện Việt Nam, các doanh nghiệp đều trong quá trình thường xuyên mở rộng hoặc thu hẹp sản xuất, kinh doanh hoặc sáp nhập, chia tách hoặc phá sản doanh nghiệp.

(ii) Phương pháp "dòng tiền chiết khấu"
Mức thu nhập của nhãn hiệu

\section{Tỷ lệ vốn hoá}

Phương pháp định giá cơ bản và phổ biến nhất trong cách tiếp cận dựa trên thu nhập là phương pháp dòng tiền chiết khấu vì cho kết quả đáng tin cậy hơn so với các phương pháp khác. Phương pháp này xác định giá trị trên cơ sở khả năng sinh lời của nhãn hiệu trong tương lai. Theo đó, giá trị hợp lý của nhãn hiệu bằng 
tổng lợi ích kinh tế mà nó mang lại trong suốt thời gian tồn tại hữu ích.

Phương pháp dòng tiền chiết khấu dùng để định giá nhãn hiệu như sau:

$$
\underline{\mathbf{v}} \quad \equiv \quad \sum_{i=1 \rightarrow n} \frac{D_{i}}{(1+K)^{i}}
$$

Theo đó:

V: Giá trị thị trường của nhãn hiệu trong thời điểm hiện tại

\section{$\frac{D_{i}}{(1+K)^{i}} \quad \begin{aligned} & \text { : là Gàm thú trị hiện tại dòng thu nhập } \\ & \text { nắ }\end{aligned}$}

i : thứ tự các năm kế tiếp kể từ thời điểm định giá $(\mathrm{i}: 1 \rightarrow \mathrm{n})$; thứ i);

$\mathrm{D}_{\mathrm{i}}$ : Dòng thu nhập (lợi nhuận sau thuế năm

n: Là số năm tương lai được lựa chọn;

$\mathrm{K}$ : Tỷ suất chiết khấu [14].

Khi định giá nhãn hiệu, hai cách tiếp cận dựa trên chi phí và cách tiếp cận dựa trên thị trường không được sử dụng do những nhược điểm của nó do đó, cách tiếp cận dựa trên thu nhập là phương pháp chính để sử dụng định giá nhãn hiệu [15]. Phương pháp dòng tiền chiết khấu là phương pháp hiệu quả để tính tỉ lệ phần trăm của phí li-xăng nhãn hiệu đối với những nhãn hiệu gắn với các đối tượng của quyền SHTT khác như sáng chế, kiểu dáng công nghiệp.

Đối với sáng chế (có thời hạn bảo hộ và tuân theo quy luật "vòng đời công nghệ"), kiểu dáng công nghiệp (có thời hạn bảo hộ) thì phương pháp dòng tiền chiết khấu này được sử dụng là phù hợp với việc xác định giá trị của sáng chế và kiểu dáng công nghiệp vì hai đối tượng này có thời hạn bảo hộ xác định. Còn đối với nhãn hiệu thì thời gian bảo hộ theo quy định của pháp luật Việt Nam là 10 năm và có thể gia hạn nhiều lần liên tiếp, mỗi lần 10 năm, do đó, với việc gia hạn liên tiếp và không hạn chế này thì thời hạn bảo hộ của nhãn hiệu có thể là "vô thời hạn" nếu chủ sở hữu gia hạn thời gian bảo hộ. Do vậy, đối với những nhãn hiệu độc lập, không gắn với các đối tượng khác của quyền SHTT thì việc sử dụng phương pháp này tỏ ra không hiệu quả vì không có thời gian bảo hộ xác định hay vòng đời công nghệ để có thể "chiết khấu" khi thu nhập giảm do sắp hết thời gian bảo hộ hay vòng đời công nghệ sắp hết. Như vậy, đối với các nhãn hiệu độc lập thì giá trị của nhãn hiệu phụ thuộc vào thu nhập của doanh nghiệp. Mặt khác, trong thực tế cho thấy nhiều giá trị tăng lên theo thời gian tồn tại nên thu nhập từ việc khai thác nhãn hiệu không thể giảm để sử dụng phương pháp dòng tiết chiết khấu. Ngoài ra, do việc xác định giá trị của nhãn hiệu dựa trên khả năng sinh lời của nhãn hiệu trong tương lai cũng chưa thể đánh giá hết được giá trị thực của nhãn hiệu bởi giá trị của nhã̃n hiệu còn phụ thuộc vào nhiều yểu tố khác như: số lượng sáng chế mà nhãn hiệu được gắn lên, khả năng sinh lời của các sáng chế này.

Bên cạnh ba cách tiếp cận thường được sử dụng trong việc định giá nhãn hiệu để xác định mức phí li-xăng khi li-xăng nhãn hiệu thì còn có các yếu tố khác ảnh hưởng tới việc xác định mức phí li-xăng, đó là:

Thứ nhất, loại hợp đồng li-xăng nhãn hiệu là hợp đồng độc quyền hay không độc quyền

(i) Hợp đồng li-xăng độc quyền (exclusive license) là một loại hợp đồng mà bên li-xăng cho phép bên nhận li-xăng độc quyền sư dụng nhãn hiệu trong phạm vi về lãnh thổ và thời gian được ghi nhận trong hợp đồng li-xăng. Trong thời hạn hợp đồng li-xăng có hiệu lực, mọi hành động sử dụng nhãn hiệu của bất kể một chủ thể nào khác, kể cả bên li-xăng trên lãnh thổ độc quyền của bên nhận li-xăng đều được coi là hành vi xâm phạm quyền sử dụng nhãn hiệu của bên nhận li-xăng. Như vậy, hệ quả pháp lý khi hợp đồng li-xăng độc quyền có hiệu lực pháp luật sẽ là:

- Bên li-xăng sẽ không được sử dụng nhãn hiệu cũng như cung cấp hoặc bán các sản phẩm hàng hoá/dịch vụ mang nhãn hiệu trong phạm vi thời gian và lãnh thổ của bên nhận li-xăng.

- Bên li-xăng cũng không được li-xăng nhãn hiệu tiếp cho bất cứ một bên thứ ba nào khác trong phạm vi thời gian và lãnh thổ của bên nhận li-xăng. 
- Quyền li-xăng nhãn hiệu cho các chủ thể tiếp theo trên lãnh thổ của bên nhận li-xăng sẽ không thuộc về bên li-xăng mà thuộc về bên nhận li-xăng độc quyền

(ii) Hợp đồng li-xăng không độc quyền (non-exclusive license) là hợp đồng mà bên li-xăng có thể sử dụng nhãn hiệu và có quyền li-xăng nhãn hiệu cho các chủ thể khác dưới hình thức li-xăng không độc quyền ngay trên lãnh thổ của bên nhận li-xăng. Như vậy, bên nhận li-xăng không phải là bên duy nhất sử dụng nhãn hiệu trong một lãnh thổ nhất định.

Trong li-xăng không độc quyền, bên nhận li-xăng không thể chuyển giao tiếp quyền sử dụng nhãn hiệu cho một bên thứ ba khác nếu không có sự đồng ý rõ ràng của chủ sở hữu nhãn hiệu [16].

Khi li-xăng độc quyền thì giá trị của nhãn hiệu bao giờ cũng "đắt" hơn khi li-xăng không độc quyền vì bên nhận li-xăng sẽ được độc quyền sử dụng nhãn hiệu đó trên phạm vi lãnh thổ của mình trong thời gian đã thỏa thuận trong hợp đồng. Vì vậy, do không có bất cứ một đối thủ cạnh tranh nào khác trong việc khai thác giá trị sử dụng của nhãn hiệu nên bên nhận li-xăng sẽ có nhiều lợi thế trong việc khai thác giá trị thương mại của nhãn hiệu trong phạm vi lãnh thổ của mình.

Trong hợp đồng li-xăng không độc quyền cần phải xác định rõ các trường hợp sau đây:

- Trường hợp 1: trong phạm vi lãnh thổ mà hợp đồng li-xăng không độc quyền có hiệu lực, cần phải làm rõ thuật ngữ "sử dụng". Mặc dù bên li-xăng không được sử dụng nhãn hiệu trong phạm vi lãnh thổ mà hợp đồng có hiệu lực nhưng bên li-xăng có được quyền bán sản phẩm mang nhãn hiệu mà hợp đồng có hiệu lực hay không?

- Trường hợp 2: quyền ký kết hợp đồng li-xăng nhãn hiệu không độc quyền với người khác vẫn thuộc về bên li-xăng nhưng cần phải làm rõ phạm vi hoạt động của người khác đó là trên lãnh thổ nào? Nếu người khác đó không sử dụng nhãn hiệu được chuyển giao trên lãnh thổ mà hợp đồng có hiệu lực thì có được quyền bán sản phẩm mang nhãn hiệu trên lãnh thổ mà hợp đồng có hiệu lực không?

Thứ hai, bên nhận li-xăng có quyền được li-xăng tiếp cho các chủ thể khác nữa không?

Nếu bên nhận li-xăng có quyền được li-xăng tiếp cho các chủ thể khác thì giá trị của nhãn hiệu trong hợp đồng li-xăng sẽ cao hơn nếu bên nhận li-xăng không có quyền li-xăng tiếp cho các chủ thể khác trong thời gian nhận li-xăng.

Thứ ba, phạm vi lãnh thổ áp dụng li-xăng và thời hạn li-xăng

Dù là hợp đồng li-xăng nhãn hiệu là hợp đồng độc quyền hay không độc quyền thì phạm vi lãnh thổ áp dụng li-xăng càng lớn thì phí li-xăng càng cao. Tương tự như thế, nếu thời hạn li-xăng càng dài thì phí li-xăng sẽ càng lớn.

Thứ tư, việc nhập khẩu song song các sản phẩm mang nhãn hiệu được li-xăng

Nhập khẩu song song là hành vi không bị coi là hành vi xâm phạm quyền SHTT. Hành vi này được pháp luật cho phép và được ghi nhận tại Luật SHTT năm 2005, sửa đổi, bổ sung năm 2009 tại Điểm b Khoản 2 Điều 125. Nhập khẩu song song là việc nhập khẩu hàng hoá chính hiệu (genius goods) đã được chính chủ sở hữu quyền SHTT hoặc chủ thể khác đưa ra thị trường nước ngoài với sự đồng ý của chủ sở hữu quyền SHTT [17]. Theo đó, nhập khẩu song song các sản phẩm mang nhãn hiệu đồng nghĩa với việc chủ sở hữu nhãn hiệu không có quyền ngăn cấm người khác thực hiện hành vi lưu thông, nhập khẩu, khai thác công dụng của sản phẩm đã được đưa ra thị trường, kể cả thị trường nước ngoài một cách hợp pháp, trừ sản phẩm không phải do chính chủ sở hữu nhãn hiệu hoặc người được phép của chủ sở hữu nhãn hiệu đưa ra thị trường nước ngoài.

Nhập khẩu song song các sản phẩm mang nhãn hiệu liên quan đến thuyết "hết quyền đối với nhãn hiệu". Hết quyền đối với nhãn hiệu được hiểu là khi chủ sở hữu đưa hoặc cho phép đưa sản phẩm mang nhãn hiệu được bảo hộ ra thị trường, chủ sở hữu không còn quyền kiểm soát hoạt động phân phối sản phẩm đó. Chủ sở hữu nhãn hiệu không có quyền ngăn chặn 
những chủ thể khác sử dụng, bán, chào hàng, nhập khẩu sản phẩm cũng như sử dụng nhãn hiệu gắn với chính sản phẩm đó [18].

Có thể lấy ví dụ minh hoạ cho thuyết "hết quyền đối với nhãn hiệu": Sau khi chai nước ngọt mang nhãn hiệu "COCA-COLA" được bán ra thị trường tại Hoa Kỳ thì quyền SHTT đối với nhãn hiệu "COCA-COLA" của Công ty Coca-Cola hoặc một chủ thể do Công ty Cocacola uỷ quyền sản xuất hoặc phân phối đối với chai nước ngọt này sẽ không còn, có nghĩa là quyền định đoạt chai nước ngọt này thuộc về người mua (gọi là “A”). Do vậy, người mua có thể tiếp tục bán chai nước ngọt này cho một bên thứ ba khác (gọi là "B") là chủ thể kinh doanh tại thị trường Việt Nam. Hành vi của $\mathrm{B}$ mua chai nước ngọt mang nhãn hiệu "COCACOLA" tại thị trường Hoa Kỳ và phân phối chai nước ngọt đó tại thị trường Việt Nam được gọi là "nhập khẩu song song".

Cùng xét trong ví dụ về nhãn hiệu "COCACOLA" nói trên, trong li-xăng nhãn hiệu sẽ có trường hợp như sau xảy ra: Chủ thể $C$ là một doanh nghiệp Việt Nam nhận li-xăng độc quyền nhãn hiệu "COCA-COLA" từ Công ty CocaCola (Hoa Kỳ) tại thị trường Việt Nam. Do đó, chỉ có duy nhất chủ thể được sử dụng nhãn hiệu "COCA-COLA" tại Việt Nam cho các sản phẩm nước ngọt đóng chai. Trong khi đang phân phối các chai nước ngọt COCA-COLA trên thị trường Việt Nam thì chủ thể $\mathrm{C}$ sẽ gặp phải sự cạnh tranh từ $\mathrm{B}$ - là doanh nghiệp thực hiện hành vi "nhập khẩu song song" các chai nước ngọt COCA-COLA. Do hành vi nhập khẩu song song là hành vi hợp pháp, không xâm phạm quyền SHTT nên tại thị trường Việt Nam, chủ thể $\mathrm{C}$ không còn là người độc quyền bán các sản phẩm mang nhãn hiệu "COCACOLA" nữa.

Như vậy, bên nhận li-xăng nhãn hiệu, đặc biệt là trong các hợp đồng li-xăng độc quyền cần chú ý:

1. Việc nhận li-xăng nhãn hiệu khác biệt với việc sử dụng/phân phối các sản phẩm mang nhãn hiệu.
2. Vấn đề nhập khẩu song song các sản phẩm mang nhãn hiệu của các chủ thể khác trên thị trường kinh doanh của bên nhận li-xăng sẽ dần tới việc bên nhận li-xăng phải cạnh tranh với các bên nhập khẩu song song các sản phẩm mang nhãn hiệu đó. Đây là một yếu tố để xem xét khi xác định phí li-xăng trong các hợp đồng li-xăng độc quyền nhãn hiệu bởi nếu không có sự cạnh tranh trong việc phân phối các sản phẩm mang nhãn hiệu được li-xăng thì phí lixăng sẽ được xác định cao hơn.

Như vậy, khi định giá nhãn hiệu để xác định mức phí li-xăng trong các giao dịch chuyển quyền sử dụng nhãn hiệu, các bên tham gia giao dịch cần phải cân nhắc kỹ về các yếu tố ảnh hưởng đến giá trị của mức phí li-xăng cũng như lựa chọn một phương pháp định giá sao cho phù hợp nhất.

4. Lựa chọn phương pháp định giá để xác định mức phí li-xăng cũng như phương thức thanh toán phí li-xăng cho phù hợp

4.1. Lựa chọn phương pháp định giá để xác định mức phí li-xăng nhãn hiệu

Như đã phân tích ở mục 3, phương pháp định giá nhãn hiệu để xác định mức phí li-xăng phù hợp nhất cho thời điểm hiện tại chính là phương pháp dòng tiền chiết khấu. Uu điểm của phương pháp này chính là:

+ Phản ánh được tất cả các nguồn lực tài chính đầu vào, các yếu tố sẽ ảnh hưởng đển giá trị của nhãn hiệu.

+ Tính toán được chính xác tỷ lệ phần trăm (\%) của mức phí li-xăng phù hợp với tiềm lực của bên nhận li-xăng.

+ Phương pháp có tính đến khả năng sinh lời trong tương lai của nhãn hiệu do đó phản ánh được đầy đủ giá trị mà nhãn hiệu mang lại.

4.2. Lựa chọn phương thức thanh toán mức phí li-xăng

Trên thực tế tại Việt Nam hiện nay đang tồn tại 5 phương thức thanh toán mức phí li-xăng như đã đề cập tại mục 2 . Thực chất, 5 phương thức thanh toán này là 3 dạng thanh toán mức phí li-xăng như sau:

Thanh toán trọn gói (Lumpsum payment) 
Thanh toán trọn gói là hình thức thanh toán mà theo đó bên nhận li-xăng thanh toán cho bên li-xăng một khoản tiền đã được tính trước khi các bên tham gia đàm phán và ký kết hợp đồng. Khoản phí li-xăng được tính trước này có thể được thanh toán trả gọn một lần hoặc một số lần vào các thời điểm kết thúc từng giai đoạn của quá trình li-xăng nhãn hiệu trong thời hạn hợp đồng.

Việc thanh toán trọn gói này vẫn tiềm ẩn những rủi ro cho cả bên nhận li-xăng và bên li-xăng:

+ Đối với bên nhận li-xăng, rủi ro sẽ đến trong các trường hợp sau:

- Bên li-xăng nhãn hiệu đã chắc chắn thu được một khoản phí chuyển giao như trong hợp đồng đã cam kết do đó có thể có những khó khăn trong việc ràng buộc trách nhiệm của bên li-xăng trong quá trình xảy ra tranh chấp quyền sở hữu/quyền sử dụng nhãn hiệu với một bên thứ ba.

- Trong trường hợp hợp đồng li-xăng nhãn hiệu là hợp đồng không độc quyền (Nonexclusive License), chính bên li-xăng sẽ tạo nên những đối thủ cạnh tranh với bên nhận li-xăng nhãn hiệu bằng cách tiếp tục chuyển giao quyền sử dụng nhãn hiệu đó cho các bên thứ ba, thậm chí bên li-xăng nhãn hiệu lại phân phối cả sản phẩm mang nhãn hiệu trong phạm vi về thời gian và phạm vi về lãnh thổ của hợp đồng. Cần lưu ý rằng, do bên li-xăng đã chắc chắn thu được một khoản phí li-xăng không đổi từ bên nhận li-xăng do đó trong trường hợp này lợi nhuận của bên li-xăng thu được tỷ lệ thuận với số lượng các bên thứ ba nhận li-xăng nhãn hiệu.

+ Đối với bên li-xăng nhãn hiệu, rủi ro sẽ đến trong các trường hợp:

- Trong quá trình đàm phán của hợp đồng, bên li-xăng có thể không nghiên cứu kỹ các yếu tố ảnh hưởng đến việc xác định phí li-xăng hoặc lựa chọn phương pháp định giá chưa phù hợp dẫn tới việc xác định mức phí li-xăng ở mức thấp hơn so với giá trị thực tế.

- Vấn đề kiểm soát chất lượng hàng hoá mang nhãn hiệu được li-xăng rất khó kiểm soát đối với trường hợp thanh toán trọn gói.
- Bên nhận li-xăng hướng tới lợi nhuận bằng cách xuất khẩu sản phẩm mang nhãn hiệu cho các bên thứ ba tại thị trường các quốc gia không bảo hộ nhãn hiệu. Điều này sẽ gây bất lợi cho bên li-xăng bởi hợp đồng li-xăng nhãn hiệu chỉ có thể ràng buộc bên nhận li-xăng xuất khẩu sản phẩm mang nhãn hiệu sang thị trường các quốc gia có bảo hộ nhãn hiệu mà không ràng buộc bên nhận li-xăng xuất khẩu sản phẩm mang nhãn hiệu sang thị trường các quốc gia không bảo hộ nhãn hiệu.

Việc thanh toán trọn gói có nguy cơ tiềm ẩn nhiều rủi ro, do vậy, các bên thường lựa chọn phương thức thanh toán này đối với việc li-xăng nhãn hiệu giữa các công ty mẹ và công ty con.

(2) Thanh toán kỳ vụ (Royalty)

Thanh toán kỳ vụ là việc bên nhận li-xăng thu được lợi nhuận do sử dụng nhãn hiệu thì phải chia một phần lợi nhuận cho bên li-xăng. Việc thanh toán kỳ vụ có thể theo các cách sau:

+ Trả kỳ vụ theo tỷ lệ phần trăm (\%) giá bán tịnh.

+ Trả theo phần trăm $(\%)$ doanh thu thuần.

+ Trả theo phần trăm (\%) lợi nhuận trước thuế của bên nhận li-xăng.

+ Kết hợp những cách nêu trên.

Việc trả phí kỳ vụ trong li-xăng nhãn hiệu có những đặc điểm sau:

(i) Sự trung thực trong khai báo lợi nhuận thu được của bên nhận li-xăng là nền tảng cho phương thức thanh toán kỳ vụ.

(ii) Tỷ lệ \% lợi nhuận hoặc số tiền mà bên li-xăng sẽ nhận được xác định ngay trong quá trình đàm phán hợp đồng.

(iii) Phí kỳ vụ của bên li-xăng có thể bằng 0 nếu lợi nhuận của bên nhận li-xăng bằng 0 , do đó, bền li-xăng nhãn hiệu phải gắn trách nhiệm của mình trong suốt quá trình hợp đồng li-xăng nhãn hiệu có hiệu lực.

Đối với phương thức thanh toán kỳ vụ thì việc trung thực trong khai báo lơi nhuận là yếu tố quan trọng và nếu thiếu yếu tố này thì không tồn tại phương thức thanh toán kỳ vụ. Đối với một quốc gia khó minh bạch trong quản lý tài 
chính thì khó có thể tồn tại phương thức thanh toán kỳ vụ. Tại Việt Nam, việc lựa chọn phương thức thanh toán kỳ vụ thông thường chỉ diễn ra trong việc li-xăng nhãn hiệu giữa các công ty mẹ và công ty con. Tỷ lệ phần trăm (\%) trong việc thu phí li-xăng nhãn hiệu giữa các công ty này cũng để ở tỷ lệ tương đối thấp nhằm mục đích bên li-xăng (công ty mẹ) không phải nộp thuế thu nhập hoặc nộp với mức thuế thu nhập ít đi theo quy định của pháp luật về thuế thu nhập doanh nghiệp.

(3) Kết hợp phương thức thanh toán trọn gói và phương thức thanh toán kỳ vụ

Trên thực tế, việc lựa chọn phương thức thanh toán kết hợp này được lựa chọn nhiều nhất. Các bên có thể lựa chọn việc bên nhận li-xăng trả trọn gói một khoản ban đầu khi ký hợp đồng và sau đó là thanh toán kỳ vụ. Phương thức thanh toán này sẽ kết hợp được những ưu điểm của 2 phương thức thanh toán trọn gói và kỳ vụ, đem lại lợi ích cho cả hai bên tham gia hợp đồng li-xăng:

+ Đối với bên li-xăng:

- Chắc chắn nhận được một khoản phí li-xăng thông qua việc bên nhận li-xăng thanh toán trọn gói một khoản tiền ban đầu khi ký hợp đồng.

- Vẫn có thể kiểm soát được chất lượng hàng hoá mang nhãn hiệu, ràng buộc những trách nhiệm của bên nhận li-xăng trong suốt quá trình thực hiện hợp đồng.

+ Đối với bên nhận li-xăng

Với việc thực hiện phương thức thanh toán kỳ vụ sau khi trả trọn gói một khoản tiền, bên nhận li-xăng vẫn có thể ràng buộc được trách nhiệm của bên li-xăng trong quá trình thực hiện hợp đồng.

\section{Kết luận}

Do là một loại giao dịch dân sự nên việc định giá nhãn hiệu để xác định mức phí li-xăng trong các giao dịch li-xăng nhãn hiệu phụ thuộc nhiều vào ý chí của các bên tham gia. Do đó, trên thực tế, các con số về mức giá trong hợp đồng li-xăng nhãn hiệu được đăng ký tại cơ quan quản lý Nhà nước (Cục SHTT) trong nhiều trường hợp chưa phản ánh đúng giá trị thực của nhãn hiệu. Ngoài ra, pháp luật Việt Nam cũng quy định các giao dịch li-xăng nhãn hiệu không nhất thiết phải đăng ký tại cơ quan quản lý Nhà nước. Theo quy định tại Khoản 2 Điều 148 Luật SHTT thì chỉ khi nào các bên tham gia thoả thuận li-xăng nhãn hiệu muốn hợp đồng li-xăng nhãn hiệu đó có giá trị pháp lý với bên thứ ba thì mới cần đăng ký tại cơ quan quản lý Nhà nước. Đối với các hợp đồng li-xăng nhãn hiệu không được đăng ký tại cơ quan quản lý Nhà nước thì giá trị của nhãn hiệu được li-xăng cũng chưa chắc đã phản ánh đúng giá trị thực của nó.

Xuất phát từ thực tiễn, để các bên tham gia thoả thuận li-xăng nhãn hiệu định giá được nhãn hiệu để xác định mức phí li-xăng hợp lý thì cần đòi hỏi năng lực của các bên tham gia thoả thuận và cũng cần có một hệ thống pháp luật quy định cụ thể và rõ ràng hơn về nguyên tắc, phương pháp và tiêu chí về định giá nhãn hiệu trong các giao dịch li-xăng nhãn hiệu. Ngoài ra, cũng cần có một cơ chế kiểm soát và áp dụng thuế thu nhập đối với các thu nhập từ phí li-xăng và các lợi ích vật chất khác khi lixăng nhãn hiệu để việc định giá nhãn hiệu trong các giao dịch li-xăng nhãn hiệu được hợp lý và chính xác hơn trong thời gian tới.

\section{Tài liệu trích dẫn}

[1] WIPO, Trademark Licensing (Module 12): IP Panorama

(http://www.wipo.int/export/sites/www/sme/en/do cuments/pdf/ip_panorama_12_learning_points. pdf), 2013, truy cập tháng 6 năm 2017.

[2] Cục SHTT, Báo cáo thường niên hoạt động SHTT năm 2015, Nhà xuất bản Khoa học Kỹ thuật, 2016.

[3] Các Hợp đồng li-xăng nhãn hiệu giữa Công ty The Phanu Group Limited (British Vigrin Islands) và Công ty một thành viên Mantra (TP. Hồ Chí Minh) năm 2008; giữa Công ty Shell Brands International (Thuỵ Sĩ) và Công ty TNHH Shell gas Viet nam (Đồng Nai); giữa TA YA Electric Wire \& Cable Co., Ltd. (Đài Loan) và Công ty cổ 
phần dây và cáp điện TA YA Việt Nam (Đồng Nai) năm 2006 được đăng ký tại Cục SHTT.

[4] Hợp đồng góp vốn bằng quyền sử dụng nhãn hiệu để thành lập Công ty Cổ phần Trung Nguyên (TP. Hồ Chí Minh) của Công ty TNHH Cà phê Trung Nguyên (Đắk Lắk) được đăng ký tại Cục SHTT năm 2006.

[5] Hợp đồng li-xăng nhãn hiệu giữa Công ty CHUGOKU Marine Paints, Ltd. (Nhật Bản) và Công ty cổ phần Sơn Hải Phòng (Hải Phòng) năm 2007 được đăng ký tại Cục SHTT.

[6] 17 hợp đồng li-xăng nhãn hiệu của Tổng công ty Thuỷ tinh và gốm sứ xây dựng Việt Nam (Viglacera) được đăng ký tại Cục SHTT.

[7] Hợp đồng li-xăng nhãn hiệu giữa Tổng công ty thuốc lá Việt Nam (Hà Nội) và nhà máy thuốc lá Sài Gòn (TP. Hồ Chí Minh) năm 2005 được đăng ký tại Cục SHTT

[8] Hợp đồng li-xăng nhãn hiệu giữa Công ty Pierre Cardin (Pháp) và Công ty Dịch vụ Tổng hợp Sài Gòn (TP. Hồ Chí Minh) đăng ký tại Cục SHTT năm 2004.

[9] Hợp đồng li-xăng nhãn hiệu giữa Công ty TCRWARE Co.,Ltd (Đài Loan) li-xăng nhãn hiệu "TAICERA, HİNH" cho Công ty cổ phần Công nghiệp Gốm sứ TAICERA (Đồng Nai) đăng ký tại Cục SHTT năm 2008.

[10] Hợp đồng li-xăng nhãn hiệu giữa Công ty Dimerco Express Holding Co., Ltd. (Bermuda) và
Công ty Liên doanh TNHH Dimerco Vietfracht (TP. Hồ Chí Minh) năm 2006.

[11] Gordon V. Smith, Susan M. Richey, Trademark Valuation, Wiley Press, 2013, pp.356.

[12] Gordon V. Smith, Susan M. Richey, Trademark Valuation, Wiley Press,, 2013, pp.357.

[13] Đoàn Văn Trường, Tuyển tập các phương pháp thẩm định giá trị tài sản, Nhà xuất bản Khoa học và Kỹ thuật, 2009, tr.357-358.

[14] Trần Nam Long, Các phương pháp định giá nhãn hiệu

(http://www.thuonghieuviet.com/news/DetailT/?g $\mathrm{ID}=7 \& \mathrm{tID}=12 \& \mathrm{cID}=36490) \quad$ (2010), truy cập tháng 5 năm 2017.

[15] John E. Elmore, The Valuation of Trademark Related Intangible Property (http://www.willamette.com/insights_journal/15/ winter_2015_8.pdf) (2015), truy cập tháng 6 năm 2017.

[16] Robert W. Gomulkiewicz, Xuan - Thao Nguyen, Danielle M. Conway, Licensing Intellectual Property: Law and Application, Wolters Kluwer Press, Second Edition, 2011, pp.106.

[17] Trần Văn Hải, Giáo trình "Chuyển giao công nghệ”, Trường Đại học Khoa học Xã hội và Nhân văn, 2017, tr.82.

[18] Nguyễn Như Quỳnh, Hết quyền đối với nhãn hiệu trong pháp luật, thực tiễn quốc tế và Việt Nam: Nhà xuất bản Chính trị - Quốc gia, 2012, tr.90.

\title{
Trademark Valuation to Define Royalty Fee in Trademark Licensing Transactions
}

\author{
Hoang Lan Phuong \\ VNU University of Social Sciences and Humanities, 336 Nguyen Trai, Thanh Xuan, Hanoi, Vietnam
}

\begin{abstract}
Trademark licensing is the method which is used widely because of its economic efficient. To be different from using tangible assets, when you license a trademark, there are many different people can use an intangible asset like trademark at a same time. In Vietnam, the price of a trademark which is licensed and the method to pay the royalty fee are very various because there are no specific regulations to direct parties of licensing agreements the suitable way to value royalty fee. The royalty fee in licensing agreements valued by parties' will because of trademark licensing is a kind of civil transactions. From the reality, to direct parties of licensing agreements the suitable way to value royalty fee which need the parties' capacity and specific regulations of principles, methods and criteria to value trademark in trademark licensing transactions.
\end{abstract}

Keywords: Valuation, trademark, royalty fee, licensing. 